\title{
LmrBPP9: A synthetic bradykinin-potentiating peptide from Lachesis muta rhombeata venom that inhibits the angiotensin-converting enzyme activity in vitro and reduces the blood pressure of hypertensive rats
}

\author{
Ernesto Lopes Pinheiro-Júnior ${ }^{\mathrm{a}}$, Johara Boldrini-França ${ }^{\mathrm{a}}$, \\ Luciana Mattoso Pires de Campos Araújo ${ }^{\mathrm{a}}$, Norival Alves Santos-Filho ${ }^{\mathrm{b}}$, Lusiane Maria Bendhack ${ }^{\mathrm{a}}$, \\ Eduardo Maffud Cilli ${ }^{\mathrm{b}}$, Eliane Candiani Arantes ${ }^{\mathrm{a}, *}$ \\ a School of Pharmaceutical Sciences of Ribeirão Preto (FCFRP), University of São Paulo, Ribeirão Preto, SP, Brazil \\ ${ }^{\mathrm{b}}$ Chemistry Institute, São Paulo State University, Araraquara, SP, Brazil
}

\section{A R T I C L E I N F O}

\section{Keywords:}

Bradykinin-potentiating peptides

ACE inhibitors

Lachesis muta rhombeata

Snake venom

Peptide synthesis

\begin{abstract}
A B S T R A C T
Bradykinin-potentiating peptides (BPPs) are an important group of toxins present in Lachesis muta rhombeata venom. They act directly at renin-angiotensin-aldosterone system, through the inhibition of angiotensin-converting enzyme (ACE). This action may contribute to the hypotensive shock observed during the envenoming by this species. Thus, the main goal of this study was the solid-phase synthesis of a BPP found in $L$. m. rhombeata venom and its in vitro and in vivo characterization in relation to ACE inhibition and hypotensive activity, respectively. The LmrBPP9 peptide was synthesized using an automated solid-phase peptide synthesizer and purified by reversed-phase fast protein liquid chromatography (FPLC). The in vitro IC50 of the synthetic peptide is $4.25 \pm 0.10 \mu \mathrm{M}$, showing a great capacity of ACE inhibition. The in vivo studies showed that LmrBPP9 induces blood pressure reduction, both in normotensive and hypertensive rats, being more pronounced in the last ones. These results agree with the in vitro results, showing that the synthetic peptide LmrBPP9 is a potential molecule to the development of a new antihypertensive drug.
\end{abstract}

\section{Introduction}

Snake venoms present a vast repertoire of bioactive compounds, many of them resembling mammal molecules, both functionally and structurally. They act similarly to endogenous components, not being, however, controlled by regulatory mechanisms. Due to that, they may cause disturbances in the physiological equilibrium of the victim $[1,2]$.

The presence of different classes of toxins, as well as their percentage in the venom, may vary among snakes' species. For this reason, snakebite victims deal with a variety of life-threatening pathologies, which may be related to neurotoxic, cytotoxic, and hemotoxic effects. About 1.8 million people are envenomed by snakes every year worldwide, with approximately 125,000 deaths. Additionally, the survivors may have to deal with life-changing conditions, directly affecting their lives in many ways. Consequently, snakebites are considered one of the world's most severe neglected tropical diseases [3].

The venom proteome of the Brazilian snake $L$. muta rhombeata revealed a remarkable presence of bradykinin-potentiating peptides (BPPs), corresponding to approximately $28 \%$ of the whole venom.
Additionally, metalloproteases, serine proteases, phospholipases $\mathrm{A}_{2}$ of the D49 subfamily, L-amino acid oxidases, C-type lectin-like proteins, among other components were also detected in this venom [4].

Historically, studies regarding BPPs had a great advance after the discovery of bradykinin by Mauricio Rocha e Silva et al., while studying the pathophysiology of Bothrops jararaca envenoming [5]. In this context, BPPs are considered one of the key physiologically active molecules present in snake venoms [6]. These peptides act unbalancing the control of arterial pressure, mainly by the inhibition of angiotensinconverting enzyme (ACE). Through this mechanism, they can decrease the production of angiotensin II, a potent hypertensive peptide, as well as the degradation of bradykinin (BK), a powerful vasodilator $[7,8]$. The hypotension and vasodilation caused by these substances actively contribute to the rapid diffusion of toxins throughout the organism, which may lead to a hypotensive shock, one of the main causes of death by venomous snakes [9].

BPPs were originally described in the venom of Bothrops jararaca as proline-rich oligopeptides, containing 5-13 amino acid residues [10]. Structurally, many of them display a pyroglutamic acid at the $\mathrm{N}$ -

\footnotetext{
* Corresponding author.

E-mail address: ecabraga@fcfrp.usp.br (E.C. Arantes).
} 
terminal and a characteristic C-terminus sequence ending on IPP [11], which is essential for binding of the peptide on ACE catalytic site $[12,13]$.

Several peptides found in snake venoms display cardiovascular activity $[14,15]$, being a great source of models for the development of new drugs. A great example is the use of the structure-function relationship of BPPs to develop captopril, the first drug designed targeting ACE inhibition, to treat hypertension [16]. Globally, this disease affects approximately $31 \%$ of the adult population [17], being an important health challenge since its complications may also cause cardiovascular and chronic kidney disturbances [18].

Therefore, studies regarding the physicochemical, structural and functional characterization of proteins and peptides present in snake venoms are of great interest in research nowadays. Because of their highly specific targets on the prey's organism, these compounds turned out to be great models to be used as lead compounds, aiming the development of new drugs $[19,20]$. On the other hand, understanding the venom and its components, as well as their mechanisms of action, is essential to better manage the therapeutics of the accidents caused by venomous animals $[21,22]$. In this work, we have screened the $L$. muta rhombeata venom for peptides belonging to the BPP family. One peptide was successfully identified, and its synthetic analogue was analyzed regarding its ACE inhibition in vitro and its in vivo vasoactive effects.

\section{Material and methods}

\subsection{Venom and reagents}

Lachesis muta rhombeata venom was kindly donated by Serpentarium Bosque da Saúde, located at Americana, São Paulo, Brazil, under IBAMA authorization 647.998. All chemicals and solvents used were of analytical grade.

\subsection{Fractionation of L. muta rhombeata venom}

The desiccated crude venom $(25 \mathrm{mg})$ was dissolved in $250 \mu \mathrm{L}$ of $0.05 \mathrm{M}$ sodium acetate buffer, $\mathrm{pH} 6.0$ and centrifuged at $13,000 \times \mathrm{g}$, at $4{ }^{\circ} \mathrm{C}$, for $10 \mathrm{~min}$, to remove insoluble components. The supernatant was collected and applied in a Sephacryl $S-100^{\circ}$ (Hiprep 16/60, GE Healthcare, UK) column pre-equilibrated with $0.05 \mathrm{M}$ sodium acetate buffer, $\mathrm{pH}$ 6.0. Fractions were eluted using the same buffer (isocratic elution), at a flow rate of $0.5 \mathrm{~mL} / \mathrm{min}$. Subsequently, fraction $\mathrm{S} 11$ was submitted to a reversed-phase chromatography, using a C18 column (218MS C18 $5 \mu \mathrm{m} 250 \mathrm{~mm} \times 2.1 \mathrm{~mm}$, Vydac, UK). Elution was performed by an acetonitrile (ACN) segmented gradient (0-100\%) using $0.1 \%(\mathrm{v} / \mathrm{v})$ trifluoroacetic acid (TFA) (solution A) and $80 \%(\mathrm{v} / \mathrm{v})$ ACN in $0.1 \%(\mathrm{v} / \mathrm{v})$ TFA (solution $\mathrm{B}$ ), at a flow rate of $0.3 \mathrm{~mL} / \mathrm{min}$. Absorbance was monitored at $214 \mathrm{~nm}$.

\subsection{ACE inhibitory activity in vitro}

ACE inhibitory activity in vitro was evaluated following the procedures described by Li et al. [23]. Some modifications were made to miniaturize the methodology, allowing the assay to be performed in $2 \mathrm{~mL}$ micro tubes.

Initially, $30 \mu \mathrm{L}$ of $5 \mathrm{mM}$ Hippuryl-His-Leu (HHL, Sigma-Aldrich Co., USA) in $100 \mathrm{mM}$ borate buffer, pH 8.3 (Sigma-Aldrich Co., USA) containing $300 \mathrm{mM} \mathrm{NaCl}$ was incubated for $5 \mathrm{~min}$, at $37^{\circ} \mathrm{C}$, with $20 \mu \mathrm{L}$ of the ACE inhibitor solution. As negative control of inhibition (100\% ACE activity), $20 \mu \mathrm{L}$ of the same buffer was used. ACE $(20 \mu \mathrm{L}$ of $100 \mathrm{mU} / \mathrm{mL}$ solution; Sigma-Aldrich Co., USA) was later added to the mixture, which was then incubated for $2 \mathrm{~h}$, at $37^{\circ} \mathrm{C}$. The catalytic reaction was stopped by adding $20 \mu \mathrm{L}$ of $\mathrm{HCl} 2 \mathrm{~N}$. The hippuric acid (HA), formed during ACE catalysis, was quantified by the incubation with $120 \mu \mathrm{L}$ of quinoline (Sigma-Aldrich Co., USA) and $40 \mu \mathrm{L}$ of benzenesulfonyl chloride (BSC, Sigma-Aldrich Co., USA) for $30 \mathrm{~min}$, at $30^{\circ} \mathrm{C}$. The chromogen HA-quinoline-BSC was diluted with $250 \mu \mathrm{L}$ of ethanol, followed by another incubation, under the same conditions. Then, $290 \mu \mathrm{L}$ of the mixture was transferred to a 96-well plate and the absorbance was measured at $492 \mathrm{~nm}$ in a microplate absorbance reader (Sunrise Basic TECAN, Austria). ACE inhibitory activity was evaluated by plotting the residual ACE activity versus the concentration of ACE inhibitor. Prism 6.0 software (GraphPad Software Inc., USA) was used to create the graphs. All the experiments were performed in triplicate.

\subsection{Mass spectrometry assays}

Molecular mass analysis were performed on a MALDI-TOF/TOF UltraFlex II mass spectrometer (Bruker Daltonics - DE), under positive ionization mode, using $\alpha$-cyano-4-hydroxy-cinnamic acid as matrix. $1 \mu \mathrm{L}$ of aqueous solution, containing the samples, was cosedimented with the matrix (1:1). Experiments were performed by scanning from a mass-to-charge ratio $(\mathrm{m} / \mathrm{z})$ of $50-1800$. De novo peptide sequencing was carried out in positive ionization mode with selected ions that were submitted to collision induced dissociation (CID), using the equipment LIFT $^{\mathrm{TM}}$ cell. The precursor ion and its fragments were selected and reaccelerated to a kinetic power of $19 \mathrm{keV}$. The laser potency was set to $60 \%$ with an incidence of more than a thousand shots, allowing the obtainment of a satisfactory signal/noise ratio. The resulting spectra were analyzed using BioTools 3.1 and FlexAnalysis 3.0 softwares (Bruker Daltonics software, DE) to deduce the amino acid sequence of the peptides.

\subsection{Peptide synthesis}

LmrBPP9 was synthesized manually through the Fmoc (N-(9-fluorenyl)methoxylcarbonyl) chemistry using the Fmoc-Pro-Wang resin (AAPPTEC, USA). The amino acid side chains were protected using 2,4,6,7-pentamethyldihydrobenzofuran-5-sulfonyl and trityl. Couplings were performed with $\mathrm{N}, \mathrm{N}$-diisopropylcarbodiimide and N-hydroxybenzotriazole under stirring for $2 \mathrm{~h}$, employing three-fold excess over the amino component in the resin. To deprotect Fmoc group, 20\% 4methyl-piperidine/dimethylformamide (DMF) was used for $20 \mathrm{~min}$. The success of each coupling was monitored by ninhydrin reaction. Cleavage of the synthesized peptide from the resin was performed with $90 \%$ TFA, $5 \%$ triisopropylsilane and 5\% water. The peptide was precipitated with ethyl ether anhydrous and separated from non-peptide material by centrifugation. Finally, the peptide was dissolved in $0.045 \%$ TFA and the mixture was centrifuged to eliminate the resin. The product was purified in a FPLC system, using a C18 column (218MS C18 $5 \mu 250 \mathrm{~mm} \times 2.1 \mathrm{~mm}$, Vydac, UK), equilibrated with $0.1 \%$ TFA. Elution was monitored at $214 \mathrm{~nm}$, using a segmented gradient of $80 \%$ ACN and $0.1 \%$ TFA. After the purification procedure, the synthetic peptide was lyophilized and stored at $-20^{\circ} \mathrm{C}$.

\subsection{In vivo ACE inhibitory activity assay}

The in vivo experiments were approved by the Animal Care and Use committee of the School of Pharmaceutical Sciences of Ribeirão Preto (FCFRP-USP), under the protocol number 14.1.268.53.0.

\subsubsection{Experimental animals}

In order to induce renovascular hypertension in rats, the 2 kidney 1 clip (2K-1C) Goldblatt model was employed [24]. Shortly, male Wistar rats, weighting 180-200 g were anesthetized for a midline laparotomy. Subsequently, a silver clip, with an internal diameter of $0.2 \mathrm{~mm}$, was placed around the left renal artery. The control group, $2 \mathrm{~K}$, was only submitted to laparotomy. After the surgery, the rats were maintained on standard rat chow, with free access to food and water, on a 12-h light-dark cycle. Six weeks after the surgery, the systolic arterial pressure was measured using the tail cuff method. The animals with a systolic pressure higher than $160 \mathrm{mmHg}$ were considered hypertensive. 
Each group was composed by four animals.

\subsubsection{Surgery for cannula implantation}

A polyethylene cannula, filled with heparinized saline, was implanted into the abdominal aorta, through the femoral artery, to record the blood pressure. Another cannula was implanted into the iliac vein, for administration of the synthetic BPP or vehicle. After the procedure, the animals were kept in individual home cages under a $12 \mathrm{~h}$ light/dark cycle, receiving standard rat chow and water ad libitum.

\subsubsection{Measurement of the mean arterial pressure}

Conscious rats had their blood pressure continuously recorded using a pressure transducer and an amplifier (AD Instruments, Australia) attached to the intra-arterial cannula. The software 4 Chart (AD Instruments, Australia) was used to determine the mean arterial pressure (MAP) under basal conditions and after the administration of the synthetic BPP or vehicle, to obtain the variation of the mean arterial pressure $(\triangle \mathrm{MAP})$.

\subsubsection{Drug administration}

Prior to drug administration, a control blood pressure was recorded for $30 \mathrm{~min}$ for arterial pressure stabilization. Later, the synthetic BPP, captopril and saline were administrated in the corresponding groups.

\subsection{Statistical analysis}

All values were expressed as mean \pm SEM. Differences between the groups in the MAP(s) were compared by one-way ANOVA, followed by Dunnett's Multiple Comparisons Test. Differences were considered statistically significant when $\mathrm{P}<0.05$.

\section{Results}

\subsection{Fractionation of L. $m$. rhombeata crude venom}

The desiccated $L$. $m$. rhombeata crude venom was submitted to the first chromatographic step, on a size exclusion column. The chromatographic profile (Fig. 1) reveals the twelve fractions obtained, named from S1 to S12. The arrow indicates the fraction that was applied in a C18 column, as second chromatographic step, which displayed ACEinhibitory activity (Fig. 1, Insert).

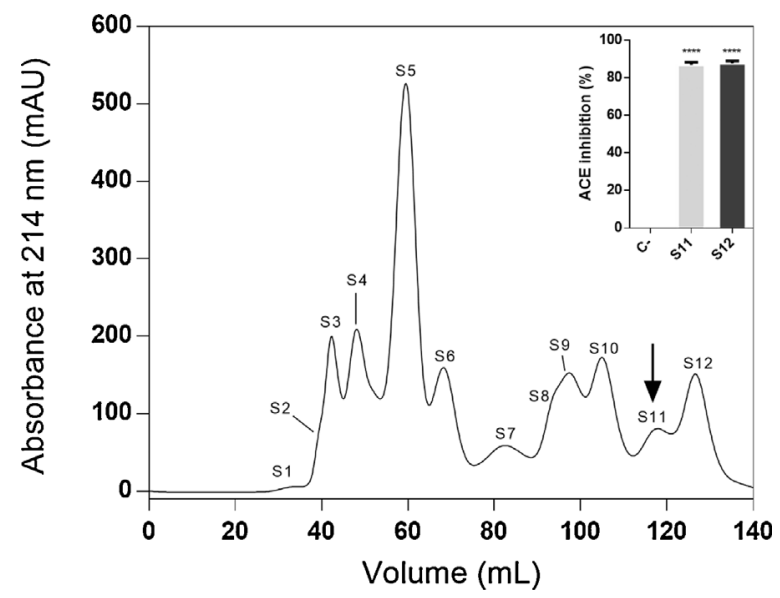

Fig. 1. Chromatographic profile of $L$. $m$. rhombeata crude venom (LmrV) on Sephacryl ${ }^{\circ} \mathrm{S}$ $100(1.6 \times 60 \mathrm{~cm})$ size exclusion column. Absorbance was monitored at $280 \mathrm{~nm}$ at $25^{\circ} \mathrm{C}$, using a FPLC ÄKTA Purifier system. LmrV $(25 \mathrm{mg}$ ) was dispersed in $250 \mu \mathrm{L}$ of $0.05 \mathrm{M}$ sodium acetate buffer, $\mathrm{pH} 6.0$ and centrifuged. The supernatant was applied on the column previously equilibrated with $0.05 \mathrm{M}$ sodium acetate buffer, $\mathrm{pH}$ 6.0. Fractions of $1.5 \mathrm{~mL}$ per tube were eluted at a flow rate of $0.5 \mathrm{~mL} / \mathrm{min}$. Insert: ACE-inhibitory activity of S11 and S12 fractions. Values were calculated based on ACE catalytic activity without the presence of inhibitors (C-). ( $* * * \mathrm{p}<0.0001)$.

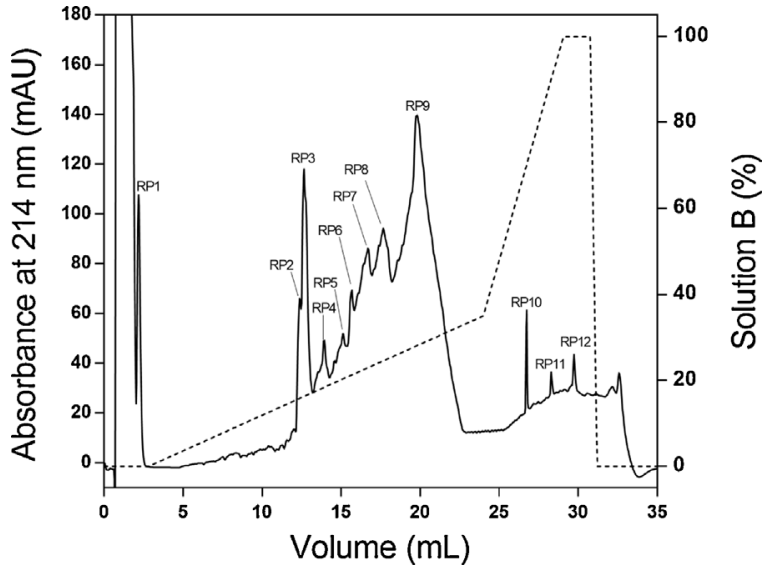

Fig. 2. Chromatographic profile of fraction $\mathrm{S} 11$ on a $\mathrm{C} 18$ column, previously equilibrated with $0.1 \%$ TFA. Fractions of $0.3 \mathrm{~mL}$ per tube were eluted at a flow rate of $0.3 \mathrm{~mL} / \mathrm{min}$ using a step concentration from 0 to $100 \%$ of solution B $(80 \% \mathrm{ACN}, 0.1 \% \mathrm{TFA})$. Absorbance was monitored at $214 \mathrm{~nm}$ at $25^{\circ} \mathrm{C}$.

Fractions S11 and S12 inhibited, respectively, 90\% and 91.5\% of ACE catalytic activity, indicating the presence of BPPs. After the first chromatographic step, fraction S11 was submitted to a reversed-phase chromatography, using a C18 column suitable for the fractionation of peptides (Fig. 2). The obtained fractions were named from RP1 to RP12.

\subsection{Screening of ACE inhibitory activity and de novo peptide sequencing}

The inhibition of ACE activity by the fractions RP1 to RP12 was performed aiming to identify which fractions contained BPPs. Fractions RP5 and RP7 to RP11 strongly inhibited ACE (Fig. 3), with ACE inhibition higher than 85\%. Fractions RP3, RP4, RP6 and RP12 also inhibited ACE activity, but with less intensity. These results indicate that fraction S11 presents different subfractions capable of inhibiting ACE activity. Eight fractions (RP5-RP12) were selected and submitted to mass spectrometry (data not shown), aiming to determine the molecular mass of the components in each one.

In fraction RP10, one peptide with $\mathrm{m} / \mathrm{z}$ of 1087 was the major component, as shown in Fig. 4A. According to the ACE inhibition of fractions RP1-12, displayed in Fig. 3, this fraction presented an inhibitory effect on ACE activity higher than $90 \%$. For this reason, de novo peptide sequencing was performed with this ion, to deduce its amino acid sequence, shown in Fig. 4B.

The sequence obtained matches a bradykinin-potentiating peptide

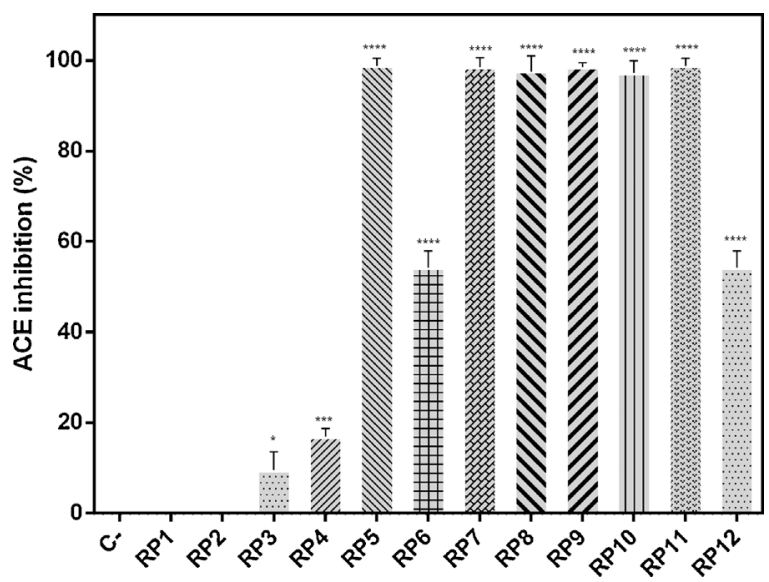

Fig. 3. In vitro ACE inhibition activity by RP-FPLC fractions. Values were calculated based on ACE catalytic activity without the presence of inhibitors (C-). Values are expressed as mean $\pm \mathrm{SD}$. $\left({ }^{*} \mathrm{p}=0.0205 ;{ }^{* * *} \mathrm{p}<0.0002 ;{ }^{* * * *} \mathrm{p}<0.00001\right.$ vs negative control). 


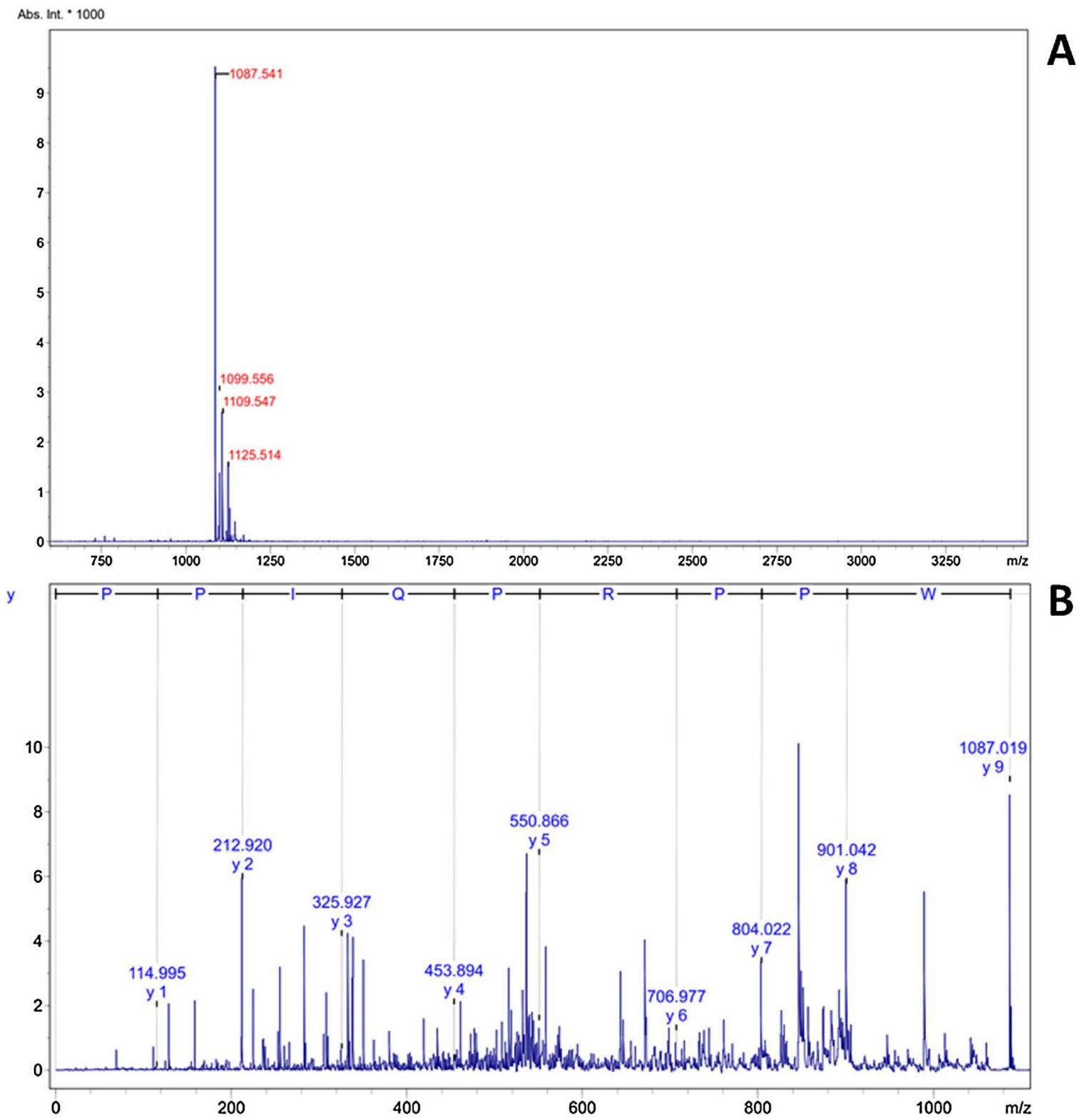

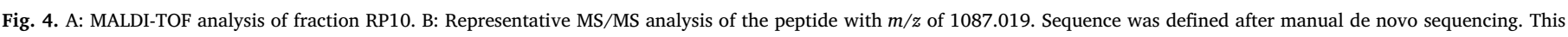
figure illustrates the y series.
1 P0DM54 (Bothrops jararaca)
2 P30424 (Bothrops insularis)
3 P85038 (Gloydius halys)
4 P0C7S4 (Bothrops neuwiedi)
5 Q27J49 (Lachesis muta rhombeata) . .WPRRPQIPP

Fig. 5. Multiple alignment of BPPs found in the venom of different species (sequences 1-4) with LmrBPP9 (sequence 5). LmrBPP9 sequence were obtained by MS/MS analysis. The highlighted box represents the consensus sequence among the aligned peptides. $\mathrm{Z}$ represents pyroglutamic acid. Each sequence is represented with its UniProt accession number and its species in parentheses. identified by Soares and colleagues [25], with nine amino acid residues (WPPRPQIPP), so-called LmrBPP9. Fig. 5 shows the multiple alignment of LmrBPP9 amino acid sequence with BPPs found in different snake venoms. Multiple sequence alignment was performed by MultAlin algorithm [26]. Subsequently, the synthetic BPP was obtained using solid-phase peptide synthesis, aiming to obtain enough sample to perform its functional characterization.

\subsection{Functional characterization of LmrBPP9}

\subsubsection{In vitro ACE inhibition assay}

Although LmrBPP9 had already been identified on $L$. muta venom, the effects of this peptide on ACE activity was not studied thus far. In this way, the $\mathrm{IC}_{50}$ of the synthetic peptide was determined in vitro using the same methodology employed on item 3.2, and compared with $\mathrm{IC}_{50}$ of captopril.

According to the residual ACE activity versus different concentrations of LmrBPP9, the synthetic peptide maintained the capability of 


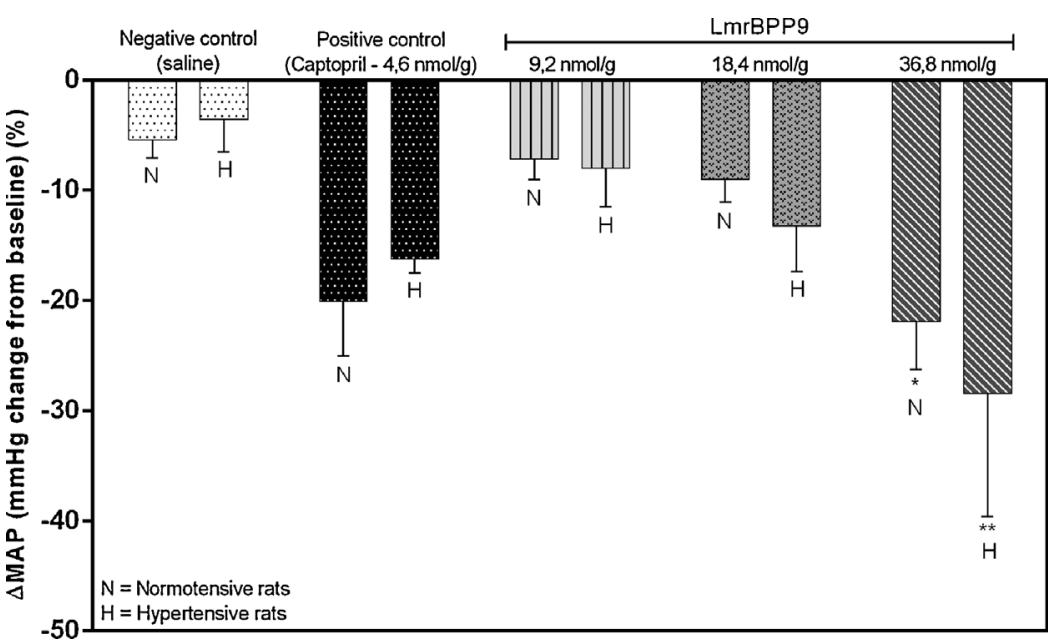

Fig. 6. Changes in MAP induced by intravenous bolus injections of different doses of LmrBPP9. A standard dose of captopril was used as positive control and saline as negative control. Drugs were injected on 6-week hypertensive 2K-1C and normotensive rats. Data are expressed as mean \pm SEM. (One-way ANOVA followed by Dunnett's Multiple Comparisons Test, ${ }^{*} \mathrm{p}<0.05 ;{ }^{*} \mathrm{p}<0.005$ vs negative control; $\mathrm{n}=4$ ). the native molecule to inhibit ACE, with an $\mathrm{IC}_{50}$ of $4.25 \pm 0.10 \mu \mathrm{M}$. Comparatively, the calculated $\mathrm{IC}_{50}$ for captopril, employed as positive control, is $8.26 \pm 0.05 \mathrm{nM}$. Although the difference between the synthetic peptide and Captorpil is considerable, the BPP presented similar $\mathrm{IC}_{50}$ values when compared to other BPPs found on Agkistrodon bilineatus venom ( $640 \mathrm{nM}, 760 \mathrm{nM}, 3630 \mathrm{nM}$ and 30,000 nM) [27].

\subsection{2. $\triangle$ MAP response to $L m r B P P 9$ and captopril in hypertensive and normotensive rats}

The difference in mean arterial pressure after peripheral injection of LmrBPP9 and captopril was evaluated in normotensive and 2K-1C renal hypertensive rats, as shown in Fig. 6. Acute injections of LmrBPP9, as well as captopril, induced hypotensive responses, when administered intravenously. The dose of $36.8 \mathrm{nmol}$ of LmrBPP9 per gram of animal induced a statistically relevant change in $\triangle \mathrm{MAP}$ (mean arterial pressure) in both normotensive and hypertensive rats. At this dose, the calculated mean difference on MAP was $-21.9 \pm 4.3 \mathrm{mmHg}$ for normotensive rats and $-28.5 \pm 11.1 \mathrm{mmHg}$ for hypertensive rats. Conversely, the doses of $9.2 \mathrm{nmol} / \mathrm{g}(\triangle \mathrm{MAP}-7.1 \pm 1.9 \mathrm{mmHg}$ and $-8.0 \pm 3.5 \mathrm{mmHg})$ and $18.4 \mathrm{nmol} / \mathrm{g} \quad(-9.0 \pm 2.0 \mathrm{mmHg}$ and $-13.2 \pm 4.1 \mathrm{mmHg}$ ) did not significantly change the mean arterial pressure in normotensive and hypertensive animals, respectively.

Furthermore, the dose of $4.6 \mathrm{nmol} / \mathrm{g}$ of captopril, which is the maximum recommended dose to manage hypertension in humans [28], did not significantly decreased the value of $\triangle \mathrm{MAP}$, with a difference of $-7.1 \pm 1.8 \mathrm{mmHg}$ and $-8.0 \pm 3.5 \mathrm{mmHg}$ for normotensive and hypertensive animals, respectively (Fig. 6).

\section{Discussion}

Cases of human envenoming by Lachesis genus are not recurrent when compared to accidents caused by other snakes' species in Brazil, such as Bothrops ssp. and Crotalus ssp. [29]. However, it may cause severe complications, including intense local pain, hemorrhage, edema, necrosis in the bite site, coagulopathies, abdominal pain, nausea, bradycardia, renal failure and, specially, an accentuated hypotension $[30,31]$. In this context, the characterization of toxins responsible for causing these symptoms are essential to better manage the therapeutic of these envenomings.

Regarding the size exclusion chromatography (Fig. 1), fractions S11 and S12 exhibited a potent inhibitory effect on ACE (90\% and 91.5\%, respectively), indicating that the BPPs present in $L$. m. rhombeata venom could be present in the last fractions of the first chromatographic step. Then, fraction S11 was submitted to a second chromatographic step, on a reversed-phase C18 column, specific for fractionating peptides. This step revealed twelve fractions, named from RP1 to RP12 (Fig. 2).

Most BPPs found in snake venoms display a general structure pattern that is represented by $<\mathrm{E}-\mathrm{X}_{\mathrm{n}}-\mathrm{P}-\mathrm{X}_{\mathrm{n}}-\mathrm{P}-\mathrm{X}_{\mathrm{n}}-\mathrm{I}-\mathrm{P}-\mathrm{P}$, with $<\mathrm{E}$ being a pyroglutamic acid and $\mathrm{X}$ any amino acid, but Cysteine [11]. According to previous studies [25] that report the cDNA library of the venom gland of $L$. muta, the sequences of BPPs in this species' venom display great similarity among each other, which may explain the similar retention time for some components.

The screening for ACE inhibitory activity (Fig. 3) of fractions RP1 to RP12 revealed that almost all the fractions (except RP1 and RP2) were capable of inhibiting ACE activity. These results agree with the venom proteome of $L$. $m$. rhombeata species, performed by Pla and colleagues [4], which showed a great relative abundance of BPPs, constituting approximately $28 \%$ of the whole venom proteins.

On mass spectrometry analysis, a peptide with $m / z$ of 1087 was the major component detected on fraction RP10 (Fig. 4A), which presented a high ACE inhibitory activity $(97.2 \pm 2.7 \%)$. For this reason, this peptide was analyzed by MS/MS and its amino acid sequence was deduced by de novo sequencing (Fig. 4B). The obtained sequence (WPPRPQIPP) matches with a BPP already identified by Soares et al. [25], but not yet characterized regarding its ACE inhibitory activity. In this way, this peptide, so-called LmrBPP9, was synthesized for further investigations.

Two classical methods were selected to evaluate the hypotensive effect of the synthetic peptide LmrBPP9. Firstly, the in vitro ACE inhibitory activity of LmrBPP9 was evaluated. Once stablished its capability to inhibit ACE, in vivo assays were performed to determine if this peptide affects arterial pressure of normotensive and 2K1C hypertensive rats.

Differently from the typical BPPs, which present a pyroglutamate at their N-terminus [12,13], LmrBPP9 has a tryptophan (Fig. 5). The synthetic peptide showed high ACE inhibitory activity in vitro, with an $\mathrm{IC}_{50}$ of $4.25 \pm 0.10 \mu \mathrm{M}$, indicating that the pyroglutamate is not crucial for the binding of the BPP on ACE catalytic site. Another atypical peptide, from Crotalus durissus cascavella, without the pyroglutamate at the N-terminus, also presented ACE inhibitory activity [32], which also supports this hypothesis.

On the other hand, LmrBPP9 presents the characteristic PP sequence at the $\mathrm{C}$-terminus, which confers resistance to hydrolysis by endogenous peptidases [33]. The study of crystal complex of somatic ACE (sACE) Cdomain and a BPP (< EGLPPRPKIPP) reported that the C-terminal prolines of the peptide strongly interacts with ACE catalytic site, creating hydrogen bonds with multiple residues of the enzyme [34]. Additionally, the presence of several proline residues in BPP sequences has armed these molecules with an intrinsic resistance to hydrolysis. In agreement with this fact, LmrBPP9 has five prolines in a primary structure of nine amino acids. Furthermore, in the same way as other BPPs already described [12,32,35-39], LmrBPP9 has an isoleucine residue next to the C-terminus prolines, which also influences the 
interaction of these peptides with ACE.

In vivo assays demonstrated that LmrBPP9 significantly decrease the arterial pressure at a dose of $36.8 \mathrm{nmol} / \mathrm{g}$, causing a $\triangle \mathrm{MAP}$ of $-21.9 \pm 4.3 \mathrm{mmHg}$ and $-28.5 \pm 11.1 \mathrm{mmHg}$ for normotensive and hypertensive rats, respectively (Fig. 6), when compared to negative control (saline). The peak of hypotensive response to intravenous bolus injection of the synthetic peptide in this dosage was greater than the standard dose of captopril, which did not present a statistically significant decrease in arterial pressure, with a $\triangle \mathrm{MAP}$ of $-7.1 \pm 1.8 \mathrm{mmHg}$ and $-8.0 \pm 3.5 \mathrm{mmHg}$ for normotensive and hypertensive rats, respectively.

Conversely, in a study employing a pool of BPPs from L. muta venom, no significant changes were observed in the mean arterial pressure of normotensive mice, when employed a dose of $200 \mu \mathrm{g}$ of the pooled peptides intraperitonially [4]. According to the authors, this dose corresponds to approximately $10 \mathrm{LD}_{50}$ s. They suggest that, despite BPPs represent a major venom component, with approximately $28 \%$ of its composition, they do not represent a serious clinical concern in the treatment of Lachesis envenomings.

In addition to our findings, several studies have demonstrated that ACE inhibition is not the only mechanism by which these peptides may potentiate the action of bradykinin (BK). ACE inhibitors may also increase the total number of $\mathrm{BK}$ binding sites, as well as preserving the high-affinity state of $\mathrm{B}_{2}$ receptors, and stopping the desensitization of the receptor by ligand, as well as decelerating the receptor endocytosis [40-43]. These evidences emphasize the importance of BPPs in the venom of this species, since one of the most remarkable symptoms of the envenoming by L. muta rhombeata is the strong hypotension in the victims [44].

\section{Conclusion}

Snake venoms are considered a great source of biologically active compounds. L. $m$. rhombeata venom presents numerous compounds able to inhibit the activity of ACE. One of the peptides identified in the venom, so-called LmrBPP9, corresponds to a bradykinin-potentiating peptide with a remarkable capability to inhibit ACE activity in vitro. Accordingly, our results demonstrated that the synthetic peptide also presents a prominent hypotensive effect on both normotensive and 2K1C hypertensive animals. Furthermore, our data supports the evidence that the presence of BPPs may play a key role in the envenoming by this species, assisting the spread of other toxins present in the venom throughout the prey's body, due to the vasodilator effect caused by bradykinin. However, further studies are essential to better understand the mechanisms by which this peptide acts on the victim's homeostasis.

\section{Funding}

The present study was supported by National Council for Scientific and Technological Development (CNPq), São Paulo Research Foundation (FAPESP; scholarship n ${ }^{\circ}$ 2014/16182-3 for Johara BoldriniFrança, scholarship n ${ }^{\circ}$ 2014/05538-1 for Norival Alves Santos-Filho and financial support $\mathrm{n}^{\circ}$ 2013/07600-3 for Center for Research and Innovation in Biodiversity and New Drugs (CIBFar) and Animal Toxins Research Support Center (NAP-TOXAN-USP).

\section{Conflict of interest}

The authors declare that this article content has no conflict of interest.

\section{References}

1] A.K. Tashima, A. Zelanis, E.S. Kitano, D. Ianzer, R.L. Melo, V. Rioli, S.S. Sant'anna, A.C. Schenberg, A.C. Camargo, S.M. Serrano, Peptidomics of three Bothrops snake venoms: insights into the molecular diversification of proteomes and peptidomes,
Mol. Cell. Proteomics 11 (11) (2012) 1245-1262.

[2] A. Zelanis, A.K. Tashima, M.M. Rocha, M.F. Furtado, A.C. Camargo, P.L. Ho, S.M. Serrano, Analysis of the ontogenetic variation in the venom proteome/peptidome of Bothrops jararaca reveals different strategies to deal with prey, J. Proteome Res. 9 (5) (2010) 2278-2291.

[3] J. Slagboom, J. Kool, R.A. Harrison, N.R. Casewell, Haemotoxic snake venoms: their functional activity, impact on snakebite victims and pharmaceutical promise, Br. J. Haematol. 177 (6) (2017) 947-959.

[4] D. Pla, L. Sanz, P. Molina-Sanchez, V. Zorita, M. Madrigal, M. Flores-Diaz, A. AlapeGiron, V. Nunez, V. Andres, J.M. Gutierrez, J.J. Calvete, Snake venomics of Lachesis muta rhombeata and genus-wide antivenomics assessment of the paraspecific immunoreactivity of two antivenoms evidence the high compositional and immunological conservation across Lachesis, J. Proteomics 89 (2013) 112-123.

[5] E.S.M. Rocha, W.T. Beraldo, G. Rosenfeld, Bradykinin, a hypotensive and smooth muscle stimulating factor released from plasma globulin by snake venoms and by trypsin, Am. J. Physiol. 156 (2) (1949) 261-273.

[6] C.L. Gomes, K. Konno, I.M. Conceicao, D. Ianzer, N. Yamanouye, B.C. Prezoto, M.T. Assakura, G. Radis-Baptista, T. Yamane, R.A. Santos, A.C. de Camargo, M.A. Hayashi, Identification of novel bradykinin-potentiating peptides (BPPs) in the venom gland of a rattlesnake allowed the evaluation of the structure-function relationship of BPPs, Biochem. Pharmacol. 74 (9) (2007) 1350-1360.

[7] S.A. Barreto, L.C. Chaguri, B.C. Prezoto, I. Lebrun, Effects of three vasoactive peptides isolated from the plasma of the snake Bothrops jararaca, Comparative biochemistry and physiology, Toxicol. Pharmacol.: CBP 149 (4) (2009) 552-558.

[8] X. Xu, B. Li, S. Zhu, R. Rong, Hypotensive peptides from snake venoms: structure, function and mechanism, Curr. Top. Med. Chem. 15 (7) (2015) 658-669.

[9] L. Sanz, J. Escolano, M. Ferretti, M.J. Biscoglio, E. Rivera, E.J. Crescenti, Y. Angulo, B. Lomonte, J.M. Gutierrez, J.J. Calvete, Snake venomics of the South and Central American Bushmasters. Comparison of the toxin composition of Lachesis muta gathered from proteomic versus transcriptomic analysis, J. Proteomics 71 (1) (2008) 46-60.

[10] A. Camargo, S.H. Ferreira, Action of bradykinin potentiating factor (BPF) and dimercaprol (BAL) on the responses to bradykinin of isolated preparations of rat in testines, Br. J. Pharmacol. 42 (2) (1971) 305-307.

[11] J.M. Sciani, D.C. Pimenta, The modular nature of bradykinin-potentiating peptides isolated from snake venoms, J. Venomous Anim. Toxins Incl. Trop. Dis. 23 (2017) 45.

[12] D. Ianzer, K. Konno, R. Marques-Porto, F.C.V. Portaro, R. Stocklin, A.C.M. de Camargo, D.C. Pimenta, Identification of five new bradykinin potentiating peptides (BPPs) from Bothrops jararaca crude venom by using electrospray ionization tandem mass spectrometry after a two-step liquid chromatography, Peptides 25 (7) (2004) 1085-1092

[13] J.H. Fernandez, G. Neshich, A.C. Camargo, Using bradykinin-potentiating peptide structures to develop new antihypertensive drugs, Genet. Mol. Res. 3 (4) (2004) $554-563$

[14] A. Munawar, M. Trusch, D. Georgieva, P. Spencer, V. Frochaux, S. Harder, R.K. Arni, D. Duhalov, N. Genov, H. Schluter, C. Betzel, Venom peptide analysis of Vipera ammodytes meridionalis (Viperinae) and Bothrops jararacussu (Crotalinae) demonstrates subfamily-specificity of the peptidome in the family Viperidae, Mol. Biosyst. 7 (12) (2011) 3298-3307.

[15] S.A. Barreto, L.C. Chaguri, B.C. Prezoto, I. Lebrun, Characterization of two vasoactive peptides isolated from the plasma of the snake Crotalus durissus terrificus, Biomed. Pharmacother. 66 (4) (2012) 256-265.

[16] D.W. Cushman, M.A. Ondetti, History of the design of captopril and related inhibitors of angiotensin converting enzyme, Hypertension 17 (4) (1991) 589-592.

[17] K.T. Mills, J.D. Bundy, T.N. Kelly, J.E. Reed, P.M. Kearney, K. Reynolds, J. Chen, J. He, Global disparities of hypertension prevalence and control: a systematic analysis of population-based studies from 90 countries, Circulation 134 (6) (2016) $441-450$.

[18] N.C.D.R.F. Collaboration, Worldwide trends in blood pressure from 1975 to 2015: a pooled analysis of 1479 population-based measurement studies with 19.1 million participants, Lancet 389 (10064) (2017) 37-55.

[19] F. De Marco Almeida, A.M. de Castro Pimenta, M.C. Oliveira, M.E. De Lima, Venoms, toxins and derivatives from the Brazilian fauna: valuable sources for drug discovery, Sheng Li Xue Bao 67 (3) (2015) 261-270.

[20] A.L. Harvey, Toxins and drug discovery, Toxicon 92 (2014) 193-200.

[21] Y.N. Utkin, Animal venom studies: current benefits and future developments, World J. Biol. Chem. 6 (2) (2015) 28-33.

[22] J.J. Calvete, Snake venomics: from the inventory of toxins to biology, Toxicon 75 (2013) 44-62.

[23] G.H. Li, H. Liu, Y.H. Shi, G.W. Le, Direct spectrophotometric measurement of angiotensin I-converting enzyme inhibitory activity for screening bioactive peptides, J. Pharm. Biomed. Anal. 37 (2) (2005) 219-224.

[24] H. Goldblatt, J. Gross, R.F. Hanzal, Studies on experimental hypertension: Ii. The effect of resection of splanchnic nerves on experimental renal hypertension, J. Exp. Med. 65 (2) (1937) 233-241.

[25] M.R. Soares, A.L. Oliveira-Carvalho, L.S. Wermelinger, R.B. Zingali, P.L. Ho, I.L. Junqueira-de-Azevedo, M.R. Diniz, Identification of novel bradykinin-potentiating peptides and C-type natriuretic peptide from Lachesis muta venom, Toxicon 46 (1) (2005) 31-38.

[26] F. Corpet, Multiple sequence alignment with hierarchical clustering, Nucleic Acids Res. 16 (22) (1988) 10881-10890.

[27] A. Munawar, A. Zahid, A. Negm, A. Akrem, P. Spencer, C. Betzel, Isolation and characterization of Bradykinin potentiating peptides from Agkistrodon bilineatus venom, Proteome Sci. 14 (2016) 1.

[28] T.H. Gill, F. Hauter, M.A. Pelter, Conversions from captopril to lisinopril at a dosage 
ratio off 5:1 result in comparable control of hypertension, Ann. Pharmacother. 30 (1) (1996) 7-11.

[29] J.L.C. Cardoso, F.O.d.S. França, F.H. Wen, C.M.S.A. Malaque, V. Haddad Junior, Animais peçonhentos no Brasil: biologia, clínica e terapêutica dos acidentes, Animais peçonhentos no Brasil: biologia, clínica e terapêutica dos acidentes, Sarvier (2003).

[30] D.C. Damico, L.G. Bueno, L. Rodrigues-Simioni, S. Marangoni, M.A. da CruzHofling, J.C. Novello, Neurotoxic and myotoxic actions from Lachesis muta mutamuta (surucucu) whole venom on the mouse and chick nerve-muscle preparations, Toxicon 46 (2) (2005) 222-229.

[31] R.C. de Souza, Aspéctos clínicos do acidente laquético, (2009).

[32] D.M. Lopes, N.E. Junior, P.P. Costa, P.L. Martins, C.F. Santos, E.D. Carvalho, M.D. Carvalho, D.C. Pimenta, B.A. Cardi, M.C. Fonteles, N.R. Nascimento, K.M. Carvalho, A new structurally atypical bradykinin-potentiating peptide isolated from Crotalus durissus cascavella venom (South American rattlesnake), Toxicon 90 (2014) 36-44.

[33] C. Lameu, H. Ulrich, Applications of snake venom proline-rich oligopeptides (BjPROs) in disease conditions resulting from deficient nitric oxide production, Drug Discov. (2013) (InTech).

[34] G. Masuyer, S.L. Schwager, E.D. Sturrock, R.E. Isaac, K.R. Acharya, Molecular recognition and regulation of human angiotensin-I converting enzyme (ACE) activity by natural inhibitory peptides, Sci. Rep. 2 (2012) 717.

[35] K.L.P. Morais, M.A.F. Hayashi, F. Bruni, M. Lopes-Ferreira, A.C.M. d. Camargo, H. Ulrich, C. Lameu, Bj-PRO-5a, a natural angiotensin-converting enzyme inhibitor, promotes vasodilatation mediated by both bradykinin B 2 and M1 muscarinic acetylcholine receptors, Biochem. Pharmacol. 81 (6) (2011) 736-742.

[36] A.C. Camargo, D. Ianzer, J.R. Guerreiro, S.M. Serrano, Bradykinin-potentiating peptides: beyond captopril, Toxicon 59 (4) (2012) 516-523.
[37] V. Rioli, B.C. Prezoto, K. Konno, R.L. Melo, C.F. Klitzke, E.S. Ferro, M. FerreiraLopes, A.C. Camargo, F.C. Portaro, A novel bradykinin potentiating peptide isolated from Bothrops jararacussu venom using catallytically inactive oligopeptidase EP24.15, FEBS J. 275 (10) (2008) 2442-2454.

[38] L.S. Wermelinger, D.L. Dutra, A.L. Oliveira-Carvalho, M.R. Soares, C. Bloch Jr., R.B. Zingali, Fast analysis of low molecular mass compounds present in snake venom: identification of ten new pyroglutamate-containing peptides, Rapid Commun. Mass Spectrom. 19 (12) (2005) 1703-1708.

[39] A. Coutinho-Neto, C.A.S. Caldeira, G.H.M.F. Souza, K.D. Zaqueo, A.M. Kayano, R.S. Silva, J.P. Zuliani, A.M. Soares, R.G. Stabeli, L.A. Calderon, ESI-MS/MS identification of a Bradykinin-Potentiating peptide from Amazon Bothrops atrox snake venom using a hybrid qq-oaTOF mass spectrometer, Toxins 5 (2) (2013) 327-335.

[40] M. Hecker, A.T. Bara, R. Busse, Potentiation of the biological efficacy of bradykinin by ACE inhibitors: a shift in the affinity of the B2 receptor? Immunopharmacology 33 (1-3) (1996) 93-94.

[41] B. Marcic, P.A. Deddish, H.L. Jackman, E.G. Erdos, Enhancement of bradykinin and resensitization of its B2 receptor, Hypertension 33 (3) (1999) 835-843.

[42] R.D. Minshall, F. Tan, F. Nakamura, S.F. Rabito, R.P. Becker, B. Marcic, E.G. Erdos, Potentiation of the actions of bradykinin by angiotensin I-converting enzyme inhibitors. The role of expressed human bradykinin $\mathrm{B} 2$ receptors and angiotensin Iconverting enzyme in CHO cells, Circ. Res. 81 (5) (1997) 848-856.

[43] S. Mueller, R. Gothe, W.D. Siems, G. Vietinghoff, I. Paegelow, S. Reissmann, Potentiation of bradykinin actions by analogues of the bradykinin potentiating nonapeptide BPP9alpha, Peptides 26 (7) (2005) 1235-1247.

[44] M.T. Jorge, I.S. Sano-Martins, S.C. Tomy, S.C. Castro, R.A. Ferrari, L.A. Ribeiro, D.A. Warrell, Snakebite by the bushmaster (Lachesis muta) in Brazil: case report and review of the literature, Toxicon 35 (4) (1997) 545-554. 